\title{
New Species of the Hover Wasp Genus Eustenogaster (Insecta: Hymenoptera: Vespidae: Stenogastrinae) from Southeast Asia
}

\author{
Fuki Saito \\ Natural History Laboratory, Faculty of Science, Ibaraki University, Mito, 310-8512 Japan \\ E-mail: fsfsaito@gmail.com
}

(Received 5 September 2008; Accepted 10 October 2008)

\begin{abstract}
Three new species of the stenogastrine genus Eustenogaster van der Vecht, 1969 are described. They are E. panaiensis sp. nov. from Panay Island, the Philippines, E. clypeata sp. nov. from Thailand, and E. vietnamensis sp. nov. from southern Vietnam. A key to the species of Eustenogaster including these new species is also given.

Key Words: Vespidae, Stenogastrinae, Eustenogaster, Philippines, Thailand, Vietnam, taxonomy, new species, dichotomous key.
\end{abstract}

\section{Introduction}

The hover wasps of the vespid subfamily Stenogastrinae, with 58 species currently recognized in seven genera (Kojima 2008), are distributed mainly in forested areas of tropical Asia and the Papua region. Because these wasps exhibit considerable diversity in social life (see Turillazzi 1991, 1996) and also form the basal clade of the social vespids (Carpenter 1982, 1991), this subfamily is considered to be a key group for understanding the origin and evolution of social behavior in wasps. Species-level taxonomy of hover wasps, however, is still rather poorly established.

Among the hover wasps, the 15 currently recognized species of the genus Eustenogaster are relatively large in body size (Saito and Kojima 2007) and most widely distributed, ranging from India to Southeast Asia. They make a camouflaged nest with an envelope. Some species are known to have a colony life led by a single egg-laying female sometimes accompanied by a few temporary helpers of adult females (Hansell 1987; Saito et al. 2009), while virgin females and males of $E$. nigra Saito and Nguyen, 2006 may undergo hibernation together in a nest (Saito et $a l$. 2006). To discuss the evolution of social behavior in the Vespidae it is necessary to study and record the unique biology of Eustenogaster with reference to a robust species-level taxonomic system. With this point in mind, I previously carried out a taxonomic revision of the genus (Saito and Kojima 2007), and additional material now allows me to recognize a further three species new to science that are described in this paper. A key to species, modified from that in Saito and Kojima (2007) to include the three new species, is also given. 


\section{Material and Methods}

External morphology and color characters of adult wasps were observed mainly on pinned-and-dried specimens. Male genitalia were dissected out, briefly cleared in $10 \% \mathrm{KOH}$, and observed in glycerin. Observations were made under a stereoscopic dissecting microscope, and drawings were made with the aid of a drawing tube. Measurements of body parts were carried out on pinned specimens under a digital microscope (VHX-5500, KEYENCE).

Acronyms for the museums/institutions in which the specimens are deposited are as follows: AMNH, American Museum of Natural History, New York, USA; IEBR, Institute of Ecology and Biological Resources, Vietnamese Academy of Science and Technology, Hanoi, Vietnam; IUNH, Natural History Collection, Ibaraki University, Mito, Japan; IUNH/FSHU, deposited in the IUNH as a long-term loan from the Faculty of Science, Hokkaido University; KIC, Collection of Kunio Iwata, held in Kanazawa University, Kanazawa, Japan; RMNH, Nationaal Natuurhistorisch Museum Naturalis, Leiden, the Netherlands.

\section{Toxonomy}

\section{Eustenogaster panaiensis sp. nov.}

(Figs 1-9, 11)

Material examined. All from Panay Island, Philippines. Holotype: + , labeled "Antique, Alojipan, Culasi, 18.xii.1982, C.K.Starr, Nest series no.570", "Holotype", and "Eustenogaster panaiensis Saito, 2009", deposited in AMNH. Paratypes: $192{ }^{\star}$ (IUNH), Antique, Alojipan, Culasi, [1 $\$ 1 \delta$, 18.xii.1982, C. K. Starr; 1 $\delta$, 19.xii.1982, C. K. Starr]; 1 $10^{\star}(\mathrm{AMNH})$, Antique, Alojipan, Culasi, [1 $q$, 18.xii.1982, C. K. Starr; $10 \hat{\text {, }}$ 19.xii.1982, C. K. Starr and M. M. Tumilap].

Diagnosis. This new species is similar to E. hauxwellii (Bingham, 1894) (for which see Saito and Kojima 2007), but can be distinguished from it by the following characters. Female: clypeus and supraclypeal area with long [short in $E$. hauxwellii] hairs; clypeus and supraclypeal area clearly demarcated by suture [not demarcated]; propodeum proportionally broader, with maximum width about 1.6 [about 1.4] times as wide as long, and densely [sparsely] hairy. Male: area between eyes and anterior ocellus sparsely [densely] punctuate; lateral furrows of pronotum absent [present]; volsella rounded; digitus with short hairs (Fig. 9) [with long hairs; Fig. 10]; aedeagus ventrally more strongly swollen (Fig. 11, vs Fig. 12 for $E$. hauxwellii); yellow markings much reduced [prominent].

Description. Female. Body length (head + mesosoma + first two terga) 18.0-19.0 $\mathrm{mm}$ (holotype: $18.5 \mathrm{~mm}$ ); forewing length $14.5-15.5 \mathrm{~mm}$ (holotype: $15.5 \mathrm{~mm}$ ). Head in frontal view about as wide as high (Fig. 1). Eye in lateral view (Fig. 2) with maximum width about 4.8 times that of gena. Anterior ocellus about 1.5 times larger in diameter than posterior ocellus; ocelli close to each other (Fig. 3); distance between anterior and posterior ocelli shorter than diameter of posterior ocellus; posterior ocelli separated from each other by distance equal to or slightly longer than their diameter.

Pronotum lacking lateral furrows. Scutum densely covered with fine punc- 

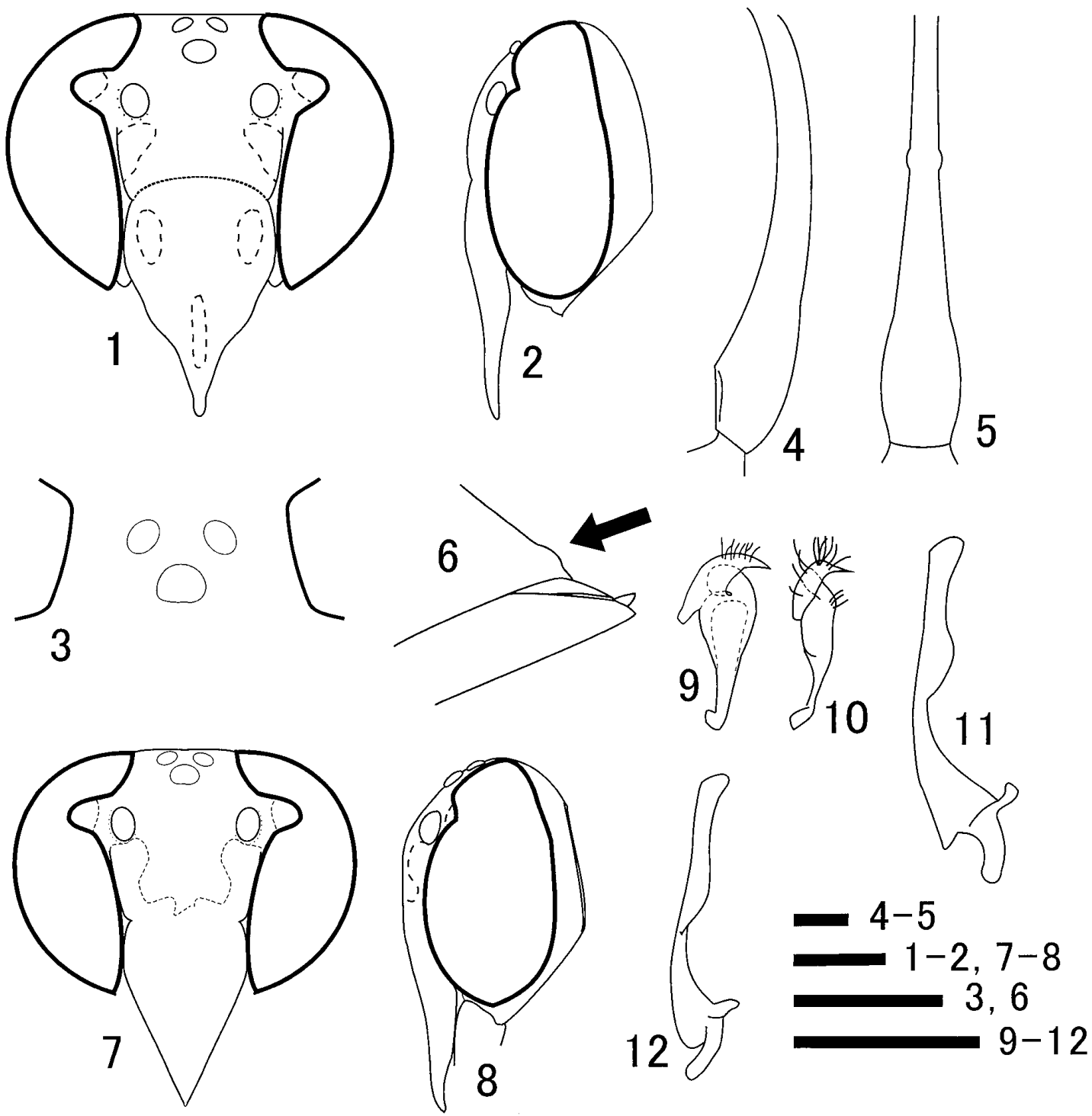

Figs 1-12. Eustenogaster panaiensis sp. nov. (1-9, 11), paratype female (1-6) and paratype male (7-9, 11), and E. hauxwellii $(10,12)$, male from West Java, Indonesia, deposited in IUNH. 1, 2, 7, 8, Head, frontal $(1,7)$ and lateral $(2,8)$ views; 3 , ocelli; 4, 5, first metasomal segment, lateral (4) and dorsal (5) views; 6 , sixth metasomal tergum, lateral view; 9 , 10, volsella with digitus, lateral view; 11, 12, aedeagus, lateral view. Scale bars: $1 \mathrm{~mm}$.

tures; interspaces between punctures narrower than puncture diameters; punctures in median area between notauli shallow. Scutellum hairy, finely punctate, strongly convex, with median ridge. Metanotum hairy, smooth-surfaced at least medially, rather strongly convex. Mesepisternum with fine and dense punctures. Propodeum hairy, without punctures.

First metasomal tergum narrow and long, 7.6-7.8 $\mathrm{mm}$ long (holotype: $7.7 \mathrm{~mm}$; Figs 4,5 ), about 5.5 times as long as its maximum width and about 5.5 times longer than its height. Sixth tergum with small tubercle (Fig. 6; arrow). 
Body shiny black. Clypeus with apical reddish-brown spot and paired lateral yellow spots. Spot below antennal socket, spot in eye emargination, small spot in posterodorsal corner of pronotum, small scrobal spot on mesepisternum (sometimes absent), paired lateral spots and posterodorsal small spots on propodeum, paired posterolateral spots on first metasomal tergum, and paired longitudinal bands or spots on second sternum (sometimes absent) all yellow. Legs dark brown; hind coxa with yellow spot posteriorly. Wings semi-hyaline, pale brown, becoming darker along anterior margin of fore wings; veins dark brown.

Male. Body length (head+mesosoma + first two terga) $17.0-18.5 \mathrm{~mm}$; forewing length $14.5-15.0 \mathrm{~mm}$. Head in frontal view about as wide as high (Fig. 7). Eyes enlarged, in lateral view strongly swollen at least in ventral half (Fig. 8), with maximum width about 7.0 times that of gena. Coloration similar to female, but clypeus and supraclypeal area just below antennal sockets yellow.

Genitalia as in Figs 9 and 11. Beak-shaped digitus set apically with several setae (Fig. 9). Penis valves of aedeagus in lateral view obliquely truncate apically, broadly emaginate ventrally (Fig. 11).

Etymology. The specific name, panaiensis, refers to Panay Island, on which the type locality of this species is located.

\section{Eustenogaster clypeata sp. nov.}

(Figs 13-17)

Material examined. All from Thailand. Holotype: $q$, labeled "THAI, Chantaburi, 21-Jun-61, 365, Yoshikawa", "29", "Holotype", and "Eustenogaster clypeata Saito, 2009", deposited in RMNH. Paratypes: 19 (KIC), Chantaburi, 21.vi.1961, K. Iwata; 1 ㅇ (IUNH/FSHU), "Chantaburi, Prew Water Fall, K. Kamol, No. 364", "70", "CT., 72/42, 1.7”, "Stenogaster n. sp. det. J. van der Vecht”; 1 ㅇ (KIC), Nabon, Tapae W[ater] F[all], 17.vii.1961, K. Iwata.

Diagnosis. This species is similar to E. micans (de Saussure, 1852) (for which see Saito and Kojima 2007), but can be distinguished from it by the more strongly convex clypeus and supraclypeal area (Fig. 14), the weakly convex lateral margins of the propodeum in posterodorsal view (Fig. 16) [gently curved in E. micans], the narrower median dark line on the supraclypeal area, and the presence of posterolateral yellow spots on the first metasomal tergum.

Description. Female. Body length (head+mesosoma+first two terga) 18.0$19.0 \mathrm{~mm}$ (holotype: $18.5 \mathrm{~mm}$ ); forewing length 13.5-14.0 $\mathrm{mm}$ (holotype: $14.0 \mathrm{~mm}$ ). Head in frontal view about as wide as high (Fig. 13), in profile (Fig. 14) with clypeus and supraclypeal area strongly convex. Clypeus with shallow and small punctures; interspaces between punctures narrower than puncture diameters. Supraclypeal area just above clypeus without punctures; space between antennal sockets with fine punctures. Anterior ocellus about 1.3 times larger in diameter than posterior one; ocelli close to each other (Fig. 15); distance between anterior and posterior ocelli shorter than diameter of posterior ocellus; posterior ocelli separated from each other by distance about equal to their diameter.

Pronotum with very shallow lateral furrow. Scutum with fine and dense punctures (interspaces between punctures narrower than puncture diameters); punctures in area between notauli smaller. Scutellum hairy, finely punctate, strongly 

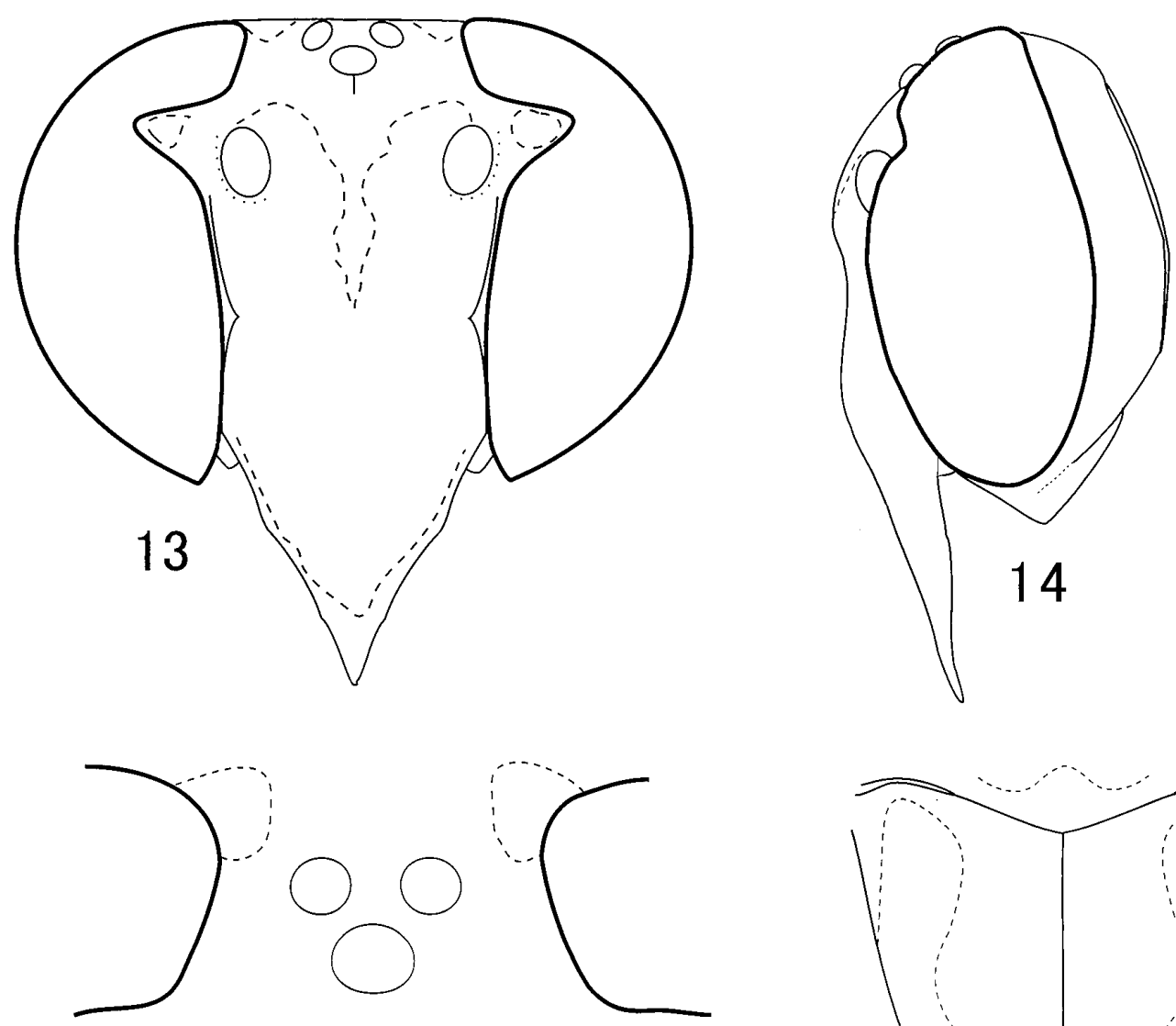

15
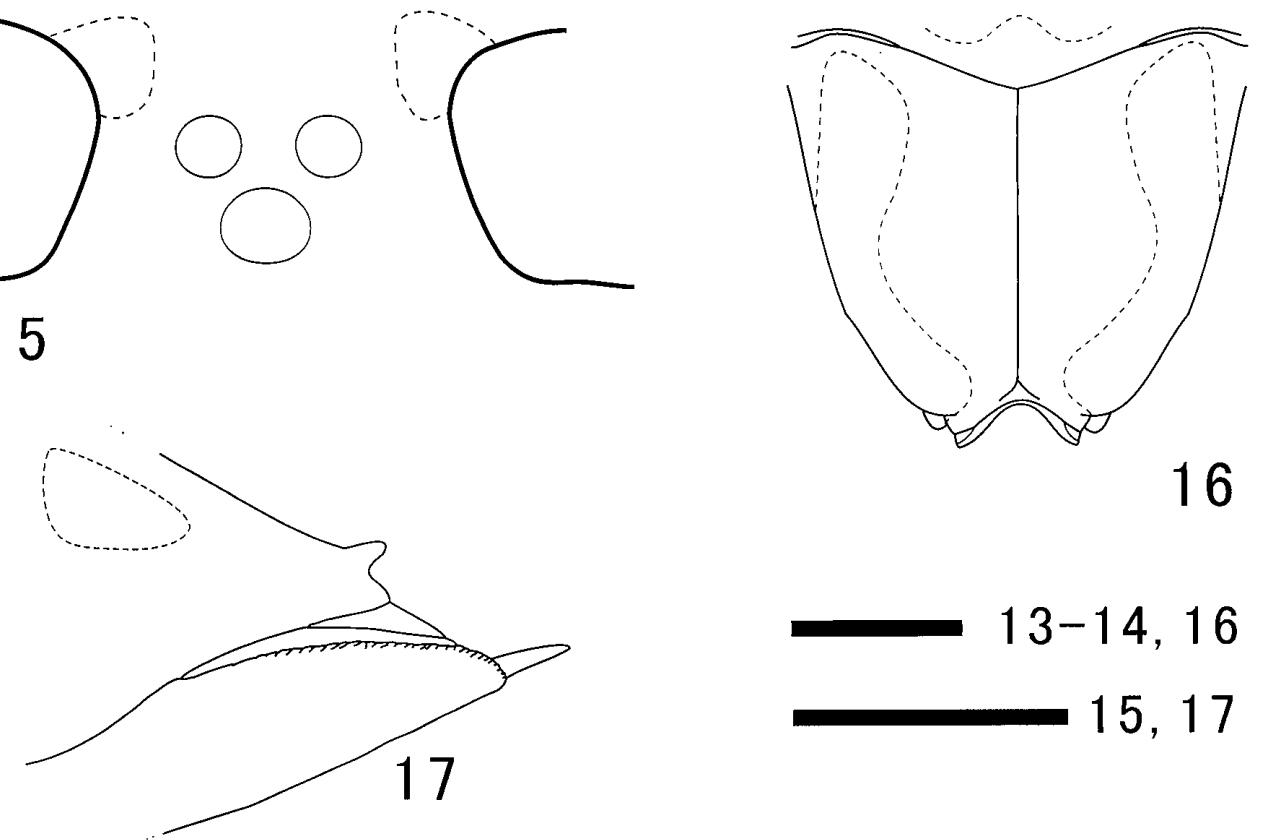

16

$13-14,16$

15,17

Figs 13-17. Eustenogaster clypeata sp. nov., holotype female. 13, 14, Head, frontal (13) and lateral (14) views; 15, ocelli; 16, propodeum, dorsolateral view; 17, sixth metasomal tergum, lateral view. Scale bars: $1 \mathrm{~mm}$.

convex, with median ridge. Metanotum hairy, smooth-surfaced at least medially, rather strongly convex. Mesepisternum with fine and dense punctures. Propodeum hairy, without punctures; lateral margins weakly convex in posterodorsal view (Fig. 16).

First metasomal tergum $7.3-7.7 \mathrm{~mm}$ long (holotype: $7.6 \mathrm{~mm}$ ), about 5.7 times as long as its own maximum width, 5.7 times longer than its maximum height. Sixth 
metasomal tergum with apically blunt spine (Fig. 17).

Body black. Antenna dark brown, but flagellum paler beneath. First metasomal tergum dark reddish-brown but black posterodorsally. Following parts yellow: clypeus and supraclypeal area except for median dark line, small spot in eye emargination, small spot beside top of inner eye margin, broad band (interrupted medially) along posterodorsal margin of pronotum, paired spots on scutellum, anterior band of metanotum, scrobal spot and large spot below it on mesepisternum, dorsolateral longitudinal bands on propodeum, posterolateral spots on first metasomal tergum, anterior band and paired lateral spots on second metasomal tergum, anterior band on third metasomal tergum, paired anterolateral bands or spots on fourth to fifth terga, and paired spots on second to fifth sterna (those on fifth sternum reduced in size). Legs brown, with following parts yellow: each one small spot on coxa and lateral sides of femur, tibia, and tarsus of fore leg; lateral sides of tibia and tarsus of mid-leg; and each one small spot on tibia and first tarsomere of hindleg. Wings pale brown, semi-hyaline, darker along anterior margin of forewing; veins brown.

Male. Unknown.

Etymology. The specific name, clypeata, refers to the strongly convex clypeus of this species.

\section{Eustenogaster vietnamensis sp. nov.}

(Figs 18-22)

Material examined. All from Vietnam. Holotype: ${ }^{\star}$, labeled "Dambri-BLōcLDong, 800m, 4/v/03" (hand written), "Dambri, Bao Loc, Lam Dong, 800m, 4/v/03", "A582", "Holotype", and "Eustenogaster vietnamensis Saito, 2009", deposited in IEBR (currently on long-term loan to IUNH). Paratypes: 20 (IEBR), Dambri, 800m, Bao Loc, Lam Dong Province, 4.v.2003, collector of Insect Systematic Department of IEBR; 10 (IUNH), Nam Cat Tien National Park, Tan Phu, Dong Nai Province, 8.viii.2005, T. P. L. Nguyen and J. Kojima.

Diagnosis. This species is similar to E. gibbosa Starr and van der Vecht, 2006 (for which see Hashim et al. 2006), but can be distinguished from it by the following characters: anterior part of scutum sparsely punctate with interspaces sometimes wider than puncture diameters [finely and densely punctate in E. gibbosa]; second metasomal tergum without transverse impression (Fig. 20) [present in E. gibbosa]; small dorsolateral spots present on first metasomal tergum [absent in $E$. gibbosa]; and yellow markings on clypeus and supraclypeal area smaller (Fig. 18) than in $E$. gibbosa.

Description. Male. Body length (head+mesosoma+first two terga) 18.0-19.0 $\mathrm{mm}$ (holotype: $19.0 \mathrm{~mm}$ ); forewing length $14.0-14.5 \mathrm{~mm}$ (holotype: $14.5 \mathrm{~mm}$ ). Head in frontal view about as wide as high (Fig. 18). Anterior ocellus about 1.3 times larger in diameter than posterior ocellus (Fig. 19); distance between anterior and posterior ocelli shorter than diameter of posterior ocellus; posterior ocelli separated from each other by distance about as great as their diameter.

Pronotum posterolaterally with fine and sparse punctures; lateral furrow present, but shallow and ending posteriorly before humeral tubercle. Scutum coarsely punctate; some interspaces in anterior part wider than puncture diameters. Scutel- 

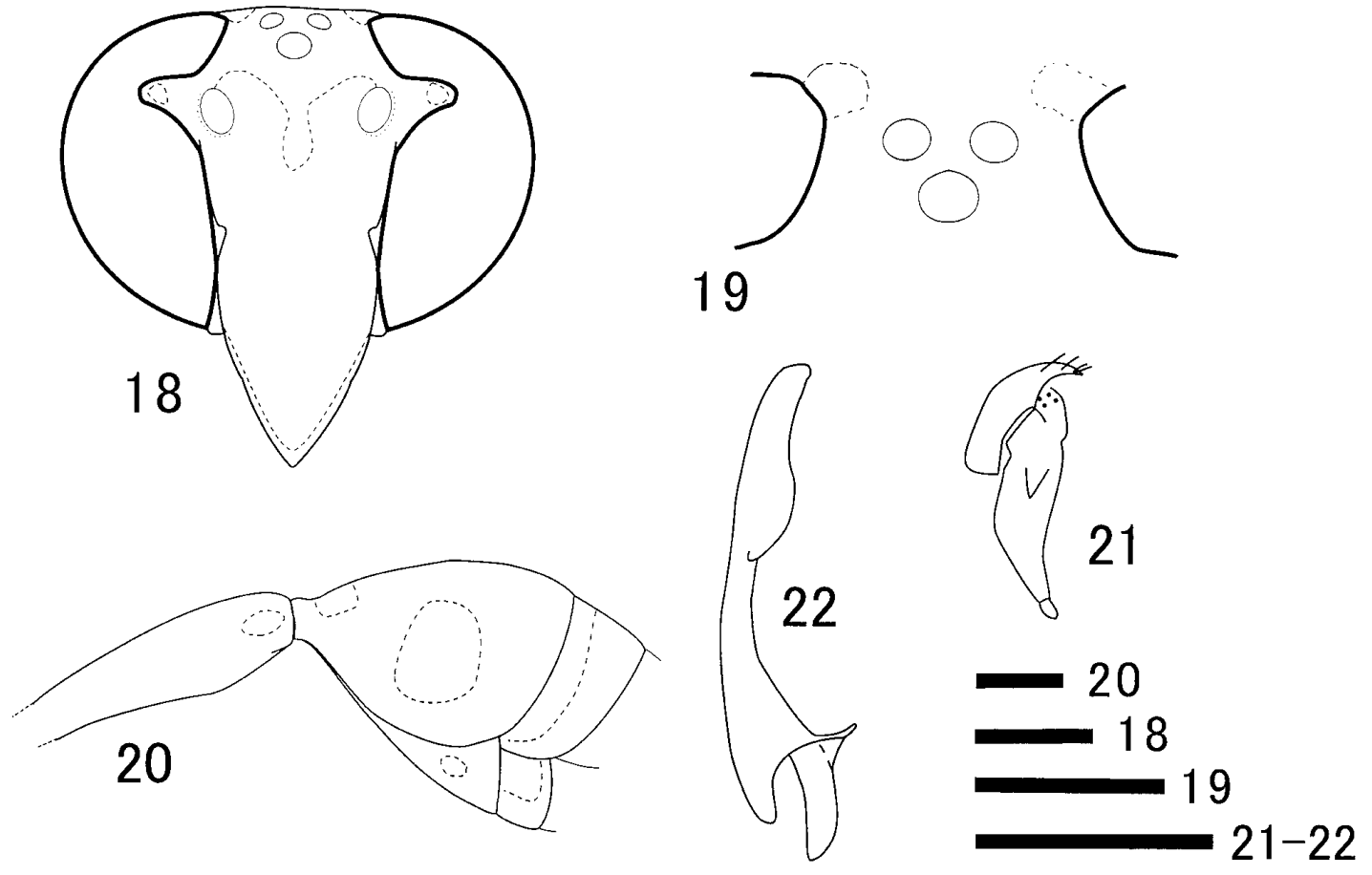

Figs 18-22. Eustenogaster vietnamensis sp. nov., paratype male. 18, Head, frontal view; 19, ocelli; 20, second metasomal tergum, lateral view; 21, volsella with digitus, lateral view; 22 , aedeagus, lateral view. Scale bars: $1 \mathrm{~mm}$.

lum hairy, densely punctate, strongly convex, with prominent median ridge. Metanotum hairy, smooth-surfaced at least medially, strongly convex. Mesepisternum with fine and sparse punctures. Propodeum hairy, without punctures.

First metasomal tergum narrow and long $(7.2-7.8 \mathrm{~mm}$ long; holotype $7.8 \mathrm{~mm}$ ), about 5.9 times longer than its maximum height and about 5.9 times longer than its maximum width. Second metasomal tergum in lateral view with dorsal margin weakly and evenly convex (Fig. 20).

Body black. Antenna dark brown, paler beneath at least in terminal two articles. Apical margin of clypeus narrowly dark brown. First metasomal tergum dark reddish-brown but black dorsally. Following parts yellow: clypeus (except apical margin) and supraclypeal area (dorsomedially emarginated) (Fig. 18), small spot in eye emargination, small spot beside top of inner eye margin, broad band (interrupted medially) along posterodorsal margin of pronotum, paired large spots on scutellum, anterior band of metanotum, scrobal spot and large spot below it on mesepisternum, paired dorsolateral longitudinal bands on propodeum, paired small dorsolateral spots on first metasomal tergum, anterior band and paired lateral spots on second tergum, paired anterolateral bands or spots on third to fifth terga, and paired spots on second to fourth sterna. Legs dark brown, with following parts yellow: lateral sides of fore leg except for entirely dark brown coxa, lateral sides of tibia and basal half of first tarsomere of mid-leg, and paired spots on coxa and each one small basal spot on tibia and first tarsomere of hind leg. Wings semihyaline, pale brown, darker along anterior margin of forewing; veins brown. 
Genitalia as in Figs 21 and 22. Beak-shaped digitus with stout median spine and apically set several setae (Fig. 21). Penis valves of aedeagus broadly emaginate ventrally (Fig. 22).

Female. Unknown.

Etymology. The specific name, vietnamensis, refers to the country from which the present species is described.

\section{Key to Species of Eustenogaster}

The present key is based on that in Saito and Kojima (2007) with the addition of several couplets with apostrophized numbers to include the three new species described in this paper. As most of the species other than the three new species are illustrated in Saito and Kojima (2007), this key may be used in combination with that work.

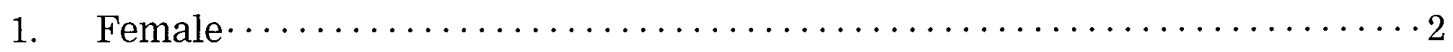

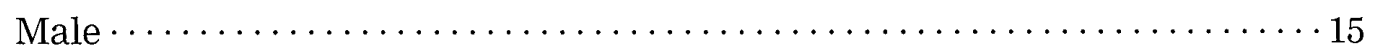

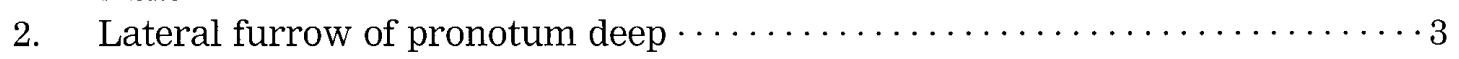

- Lateral furrow of pronotum shallow or absent $\ldots \ldots \ldots \ldots \ldots \ldots \ldots \ldots \ldots$

3. Lateral furrow of pronotum reaching humeral tubercle $\ldots \ldots \ldots \ldots \ldots \ldots \ldots$

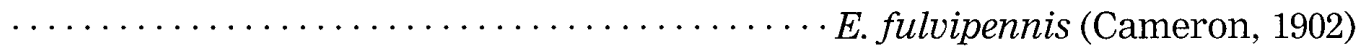

Lateral furrow of pronotum not reaching humeral tubercle $\ldots \ldots \ldots \ldots \ldots$

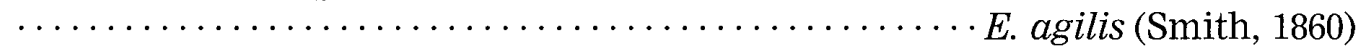

4. Lateral sides of pronotum and dorsal part of mesepisternum dull, densely and sometimes rugosely punctate. Second metasomal tergum distinctly convex

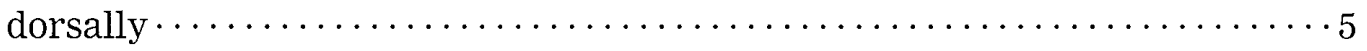

- Lateral sides of pronotum and dorsal part of mesepisternum finely punctate. Second metasomal tergum only slightly convex dorsally $\cdots \cdots \cdots \cdots \cdots \cdots \cdot 7$

5. First metasomal tergum in dorsal view barely widened some distance behind level of spiracles, then abruptly widening in posterior one-fifth of the tergum; second metasomal tergum weakly convex dorsally

E. fraterna (Bingham, 1897)

- First metasomal tergum in dorsal view gradually widening posteriorly from level of spiracles; second metasomal tergum strongly convex dorsally $\cdots \cdots \cdot 6$

6. Clypeus and propodeum entirely black $\cdots \cdots E$. nigra Saito and Nguyen, 2006 Clypeus usually with yellow spot of variable size, rarely entirely black; propodeum with paired apical yellow spots $\cdots \cdot \cdots \cdot$. E. scitula (Bingham, 1897)

7. Space between antennal sockets with rather sparse, shallow punctures. Scutum with sparse, shallow punctures $\cdots \cdot \ldots \cdot \ldots \cdot \cdots$. E. eximia (Bingham, 1890)

- Space between antennal sockets densely, and sometimes rugosely, punctate. Scutum densely covered with well-defined punctures $\ldots \ldots \ldots \ldots \ldots \ldots \cdots, 8$

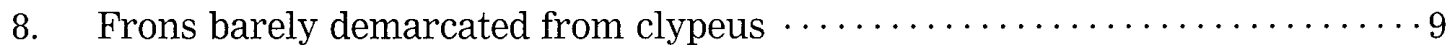
Frons clearly demarcated from clypeus by suture $\cdots \cdots \cdots \cdots \cdots \cdots \cdots \cdot \ldots \cdot 9^{\prime}$

9. Supraclypeal area just above clypeus with dense, well-defined punctures; interspaces between punctures narrower than puncture diameters $\cdots \cdots \cdots 10$

- Supraclypeal area just above clypeus with sparse, shallow punctures; interspaces between punctures wider than puncture diameters $\cdots \cdots \cdots \cdots \cdots \cdot 11$

$9^{\prime}$. Clypeus with short hairs. Sixth metasomal tergum with sharp spine. Clypeus 
and supraclypeal area yellow with median dark line. Eye emarginations en-

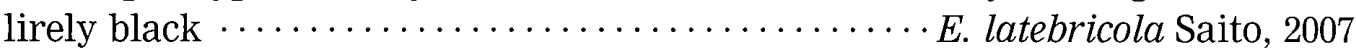

- Clypeus with long hairs. Sixth metasomal tergum with small tubercle. Clypeus with paired lateral yellow spots. Supraclypeal area with yellow spot below antennal socket. Eye emargination with yellow spot $\ldots \ldots \ldots \ldots \ldots \ldots$.

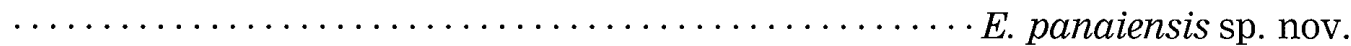

10. Extreme apex of clypeus sharply pointed $\cdots \cdots E$. hauxwellii (Bingham, 1894)

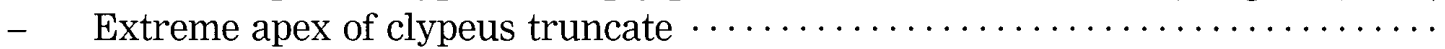
...................... calyptodoma (Sakagami and Yoshikawa, 1968)

11. Median impunctate area in supraclypeal area smaller than anterior ocellus .

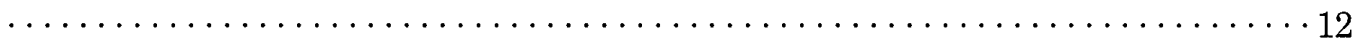

- Median impunctate area in supraclypeal area much larger than anterior

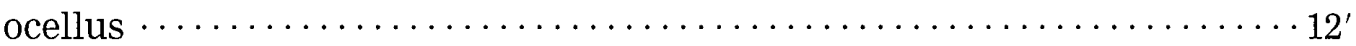

12. Area below each antennal socket covered with long, dense hairs. Scutum with large, sparse punctures; interspaces between punctures wider then puncture

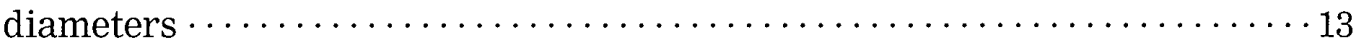

- Area below each antennal socket covered with short hairs. Scutum with small, dense punctures; interspaces between punctures narrower than punc-

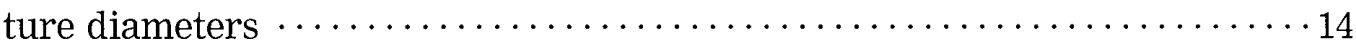

12'. Second metasomal tergum with distinct transverse impression (sometimes weak in specimens from Mentawai Islands) separating somewhat swollen posterior two-fifths from anterior part. Sixth metasomal tergum with blunt tubercle. Clypeus yellow except for median dark line ....................

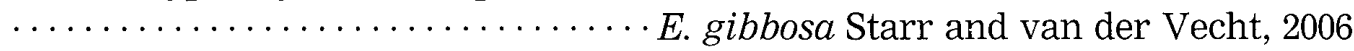

- Second metasomal tergum lacking transverse impression. Sixth metasomal tergum with spine. Clypeus entirely yellow $\cdots . . \cdots \cdots \cdots \cdot$. clypeata sp. nov.

13. Space between antennal sockets rugosely punctate. Clypeus extensively marked with yellow.$\cdots \ldots \ldots \ldots \ldots \ldots \ldots \ldots$. E. spinicauda Saito, 2007 Space between antennal sockets with dense, fine punctures. Clypeus black except for small lateral yellow spots..$\ldots \ldots \ldots \ldots \ldots$. fumipennis Saito, 2007

14. Eye emargination marked with yellow $\cdots \cdots \cdots \cdot$. micans (de Saussure, 1852)

- $\quad$ Eye emargination black $\cdots \ldots \ldots \ldots \ldots \ldots \ldots \ldots$. . palavanica Reyes, 1988

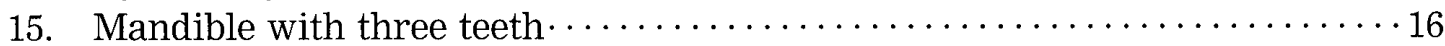

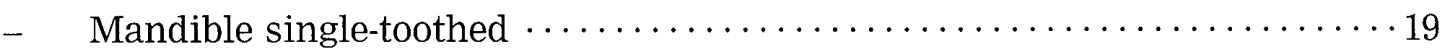

16. Mandible with median tooth reduced to slight convexity and proximal tooth reduced in size ............................ agilis (Smith, 1860)

All three mandibular teeth more or less distinct, apically blunt $\ldots \ldots \cdots \cdots 17$

17. Second metasomal tergum weakly convex dorsally

Second metasomal tergum strongly convex dorsally $\cdots \ldots \ldots \ldots \ldots \ldots \ldots+18$

18. Second metasomal tergum strongly swollen dorsally in anterior half. Clypeus and propodeum entirely black $\cdots \cdots \cdots \cdots \cdots$. nigra Saito and Nguyen, 2006 Second metasomal tergum evenly and less strongly convex dorsally. Clypeus usually with median yellow spot of variable size, rarely entirely black; propodeum as a rule with paired apical yellow spots $. . . \ldots \ldots \ldots \ldots \ldots .$.

E. scitula (Bingham, 1897)

19. Lateral furrow of pronotum deep, distinctly striate, reaching humeral tubercle. Clypeal apex with median impunctate ridge $\ldots \ldots \ldots \ldots \ldots \ldots \ldots \ldots$ 
- Lateral furrow of pronotum shallow or absent. Clypeal apex convex medially

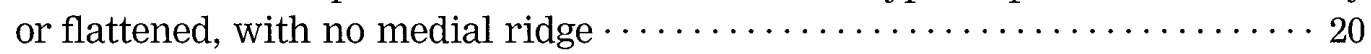

20. Clypeus flattened dorsally, smoothly continuous to supraclypeal area. Digitus without median spine and set apically with dense, long hairs $\cdots \cdots \cdots \cdots \cdot 20^{\prime}$ Clypeus weakly convex dorsally, separated from supraclypeal area by shallow depression or short suture. Digitus with median spine and set apically with

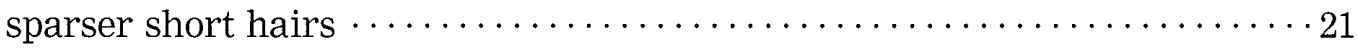

$20^{\prime}$. Supraclypeal area between antennal sockets densely punctate; interspaces between punctures narrower than puncture diameters. Yellow spots present above antennal sockets and on vertex and pronotal collar...............

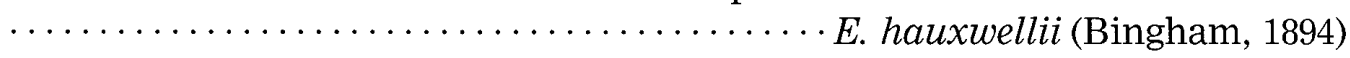
Supraclypeal area between antennal sockets sparsely punctate; some interspaces between punctures wider than puncture diameters. Yellow spots absent above antennal sockets and on vertex and pronotal collar ............

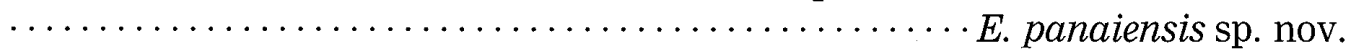

21. Clypeus separated from supraclypeal area by short suture...$\ldots \ldots \ldots \ldots$ ...................................... latebricola Saito, 2007 Clypeus separated from supraclypeal area by shallow depression $\cdots \cdots \cdots \cdot 22$

22. Median impunctate area in supraclypeal area as large as or larger than anterior ocellus (sometimes slightly smaller than anterior ocellus in E. micans) $\cdots \cdots 23$

- Median impunctate area in supraclypeal area somewhat smaller than ante-

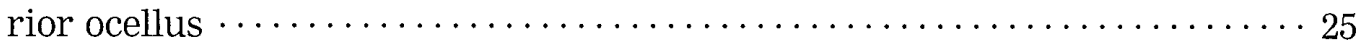

23. Second metasomal tergum barely convex dorsally. Supraclypeal area finely

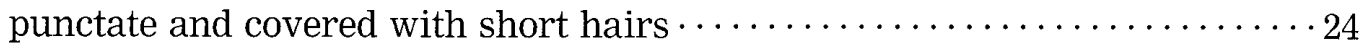

- Second metasomal tergum more or less distinctly convex dorsally (Fig. 20). Supraclypeal area medially impunctate and without hairs $\ldots \ldots \ldots \ldots \cdots 24^{\prime}$

24. Area around ocelli with dense, fine punctures. Eye emargination filled with

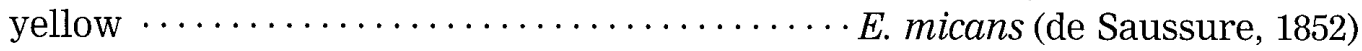

- Area around ocelli with larger punctures. Eye emargination with small yellow spot or entirely black $\cdots \cdots \cdots \cdots \cdots \cdots \cdots \cdots \cdot$. palavanica Reyes, 1988

24 '. Second metasomal tergum with transverse impression separating swollen posterior two-fifths from anterior part. First metasomal tergum lacking small dorsolateral yellow spots ........... gibbosa Starr and van der Vecht, 2006

- Second metasomal tergum without transverse impression (Fig. 20). First metasomal tergum with small dorsolateral yellow spots $\ldots \ldots \ldots \ldots \ldots \ldots \ldots$

25. Pronotum with paired deep, dorsolateral furrows behind pronotal collar ..... ...................... calyptodoma (Sakagami and Yoshikawa, 1968)

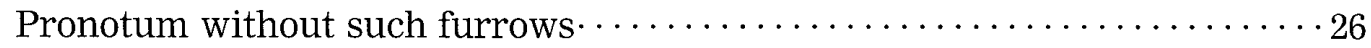

26. Head with yellow spot above each antennal socket and paired yellow spots on

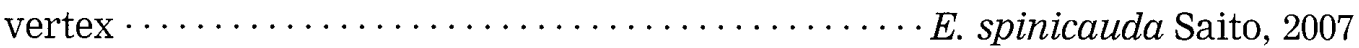

- Head without yellow spots above antennal socket or on vertex.......... ...................................... luzonensis (Rohwer, 1919) 


\section{Acknowledgments}

The present study was partly supported by a Grant-in-Aid for Japan Society for the Promotion of Science (JSPS) Fellows (no. 18 -5900). I thank J. Kojima, L. T. P. Nguyen, R. Ohgushi, and C. K. Starr for providing me with valuable specimens.

\section{References}

Carpenter, J. M. 1982. The phylogenetic relationships and natural classification of the Vespoidea (Hymenoptera). Systematic Entomology 7: 11-38.

Carpenter, J. M. 1991. Phylogenetic relationships and the origin of social behavior in the Vespidae. Pp. 7-32. In: Ross, K. G. and Matthew, R. W. (Eds) The Social Biology of Wasps. Cornell University Press, Ithaca, New York.

Hansell, M. H. 1987. Elements of eusociality in colonies of Eustenogaster calyptodoma (Sakagami and Yoshikawa). Animal Behaviour 35: 131-141.

Hashim, R., Starr, C. K. and Turillazzi, S. 2006. Nest and species description of the SoutheastAsian hover-wasp Eustenogaster gibbosa n. sp. (Hymenoptera Vespidae). Tropical Zoology 19: 289-296.

Kojima, J. 2008. Checklist of the Species of the Subfamily Stenogastrinae (Hymenoptera: Vespidae). Available on November 2008 from http://www.ipc.ibaraki.ac.jp/ jkrte/wasp/ steno/top.html.

Saito, F. and Kojima, J. 2007. A taxonomic revision of the hover wasp genus Eustenogaster van der Vecht (Insecta: Hymenoptera; Vespidae, Stenogastrinae). Zootaxa 1556: 1-30.

Saito, F., Nguyen, L. T. P., Carpenter, J. M. and Kojima, J. 2006. A new Eustenogater [sic] species (Hymenoptera: Vespidae; Stenogastrinae), the first hover wasp known to overwinter on the nest. American Museum Novitates 3534: 1-11.

Saito, F., Nguyen, L. T. P. and Kojima, J. 2009. Colony cycle of a "temperate" hover wasp, Eustenogaster nigra, with special reference to overwintering of males in an enveloped nest together with virgin females (Hymenoptera, Vespidae, Stenogastrinae). Insectes Sociaux 56: 49-54 (available as the on-line first DOI 10.1007/s00040-008-1036-z).

Turillazzi, S. 1991. The Stenogastrinae. Pp. 74-98. In: Ross, K. G. and Matthew, R. W. (Eds) The Social Biology of Wasps. Cornell University Press, Ithaca, New York.

Turillazzi, S. 1996. Adults and nest of Liostenogaster pardii n. sp. (Hymenoptera: Stenogastrinae). Tropical Zoology 9: 19-30. 